\title{
EDITORIAL
}

\section{ERC-ESICM guidelines for prognostication after cardiac arrest: time for an update}

\author{
Claudio Sandroni $i^{1,2^{*}}$ (D, Antonello Grippo ${ }^{3,4}$ and Jerry P. Nolan ${ }^{5,6}$
}

(0) 2020 Springer-Verlag GmbH Germany, part of Springer Nature

\begin{abstract}
About two-thirds of patients who are comatose after resuscitation from cardiac arrest die before hospital discharge, of whom two-thirds die from neurological injury [1]. In these patients, prognostication is crucial in informing clinicians and patient's relatives so that appropriate care can be provided.

In their 2015 guidelines on post-resuscitation care, the European Resuscitation Council and European Society of Intensive Care Medicine (ERC-ESICM) included a multimodal algorithm for predicting poor neurological outcome after cardiac arrest [2]. This algorithm is applicable to comatose, unsedated patients with a Glasgow Motor Score $M \leq 2$ at $\geq 72 \mathrm{~h}$ after return of spontaneous circulation (ROSC) and includes bilateral absence of ocular reflexes and/or N20 waves of short-latency somatosensory evoked potentials (SSEPs) as first-line predictors, and a combination of second-line predictors including status myoclonus, high neuron-specific enolase (NSE) values, unreactive burst-suppression or status epilepticus on EEG, and signs of diffuse anoxic injury on brain CT or MRI. All these predictors individually had a high specificity and precision. However, their combination has yet to be prospectively validated.
\end{abstract}

Recently, three studies from different groups of investigators have retrospectively assessed the accuracy of the 2015 ERC-ESICM prognostication algorithm. A singlecentre study from Zhou et al. [3] included 288 patients who remained unconscious for $\geq 24 \mathrm{~h}$ after ROSC. Among 207 survivors on day 3, the ERC-ESICM algorithm predicted an unfavourable 6-month outcome with

\footnotetext{
*Correspondence: claudio.sandroni@policlinicogemelli.it ${ }^{1}$ Department of Intensive Care, Emergency Medicine and Anaesthesiology, Fondazione Policlinico Universitario "Agostino Gemelli"-IRCCS, Largo Francesco Vito, 1, 00168 Rome, Italy

Full author information is available at the end of the article
}

a $0 \%$ false-positive rate (FPR), compared with $15 \%$ FPR of an algorithm proposed in 2006 by the American Academy of Neurology [4]. The study was based on a retrospective chart review, which resulted in selection bias and missing data on several predictors. For instance, SSEPs and NSE were recorded in only $19 \%$ and $20 \%$ of patients, respectively, potentially underestimating their sensitivity. Among 174 patients who had poor outcome, only 48 (28\%) were identified by the ERC-ESICM algorithm.

A subsequent single-centre validation study published recently in this journal included 485 patients who were comatose on clinical examination performed off sedation between 48 and $72 \mathrm{~h}$ after ROSC [5]. Of these patients, 273 died or had severe neurological disability at 3 months, and the ERC-ESICM algorithm predicted poor outcome with 0\% FPR in 155 (57\%) of them. The study was conducted using prospectively collected data, which ensured a systematic use of prognostication indices and largely explains this higher sensitivity in comparison with that of the previous study.

Finally, in this issue of Intensive Care Medicine, Moseby-Knappe et al. [6] retrospectively applied the ERC-ESICM algorithm in 585 patients from the targeted temperature management (TTM) trial [7]. Among 205 patients who were comatose with $M \leq 2$ on day 4 after ROSC and after stopping sedation, 191 had poor outcome, of whom 103 fulfilled the ERC-ESICM criteria (54\% sensitivity). Again, no falsely pessimistic prediction occurred.

All three of these studies defined poor outcome consistently as severe neurological disability, persistent vegetative state or death, based on current consensus $[8,9]$. However, they are based on low-certainty evidence due to their retrospective design and low power; they are also affected by confirmation bias-results of most poor outcome predictors were not blinded to the treating team, and some of them were used for deciding treatment

\section{Springer}


withdrawal, creating a self-fulfilling prophecy. This bias cannot be completely avoided in prognostication practice [9], On the other hand, studies conducted in populations where active treatment is not withdrawn in patients with severe post-anoxic neurological injury confirmed a consistent 0\% FPR for predictors recommended in the ERCESICM guidelines [10, 11].

The major limitation of the current ERC-ESICM multimodal prognostication strategy is that it applies only to a minority of patients who are comatose after cardiac arrest. When no first-line predictor or no combination of second-line predictors is present, the outcome remains indeterminate. In the Bongiovanni and the MosebyKnappe study, this occurred in $68 \%$ and $50 \%$ of cases, respectively (Table 1).

There are two potential strategies to reduce this uncertainty. A first strategy is to increase algorithm sensitivity for poor outcome. With this aim, Bongiovanni et al. reassessed electroencephalography (EEG) in the 330 indeterminate patients using the 2012 American Clinical Neurophysiology Society [ACNS] EEG terminology [12] in search of new "highly malignant" patterns (suppression or ACNS-defined burst-suppression). This led to the identification of 11 additional patients, of whom 10 had a poor outcome (specificity 99.5\%; 95\% CI 97.4-99.9\%). Moseby-Knappe et al. directly replaced the ERC-ESICM criteria for unfavourable EEG with these "highly malignant" patterns and assessed them in combination with the other second-line predictors. This updated ERCESICM algorithm confirmed 0\% FPR and identified three additional patients with poor outcome, raising sensitivity to $56 \%$. In an additional exploratory analysis, the authors increased the threshold of the motor response for entering the algorithm from $M \leq 2$ to $M \leq 3$, i.e. including patients with abnormal flexion to pain. This also increased sensitivity, allowing the identification of six additional patients while maintaining $0 \%$ FPR.

A second strategy to reduce uncertainty is to extend prognostication to patients with good neurological outcome. In the Bongiovanni study, a "benign" EEG pattern (continuous, reactive, normal-voltage background with no superimposed discharges) was present in $250 / 330$ patients with indeterminate outcome, 184 of whom had good neurological recovery (positive predictive value 66.1 [65-67.5]\%). Interestingly, about one quarter of these patients had delayed awakening, a common occurrence in TTM-treated patients who recover consciousness after cardiac arrest [13]. Prediction of good outcome may be important when making decisions about prolonging life support in patients whose outcome appears indeterminate.

In summary, these three studies consistently confirmed the accuracy of the ERC-ESICM multimodal prognostication strategy in avoiding a falsely pessimistic prediction. This high specificity was confirmed when the 2014 criteria for malignant EEG were replaced with a more recent classification of EEG pattern. Besides improving sensitivity of prediction, this classification also enables a good interrater reliability, favouring guidelines' implementation. Another major step in this direction will be the adoption of standardised and reproducible methods for the assessment of clinical predictors, such as automated pupillometry for pupillary light reflex [14]. This and other recent advances in prognostication now have been systematically reviewed by the ESICM and ERC [15] and the results of this review will inform their upcoming guidelines on postresuscitation care. Future prospective studies limiting both confirmation and selection bias and specifically addressing the role of extracerebral causes of death are warranted to improve the quality of evidence in prognostication after cardiac arrest.

\footnotetext{
Author details

${ }^{1}$ Department of Intensive Care, Emergency Medicine and Anaesthesiology, Fondazione Policlinico Universitario "Agostino Gemelli"-IRCCS, Largo Francesco Vito, 1, 00168 Rome, Italy. ${ }^{2}$ Institute of Anaesthesiology and Intensive Care Medicine, Università Cattolica del Sacro Cuore, Rome, Italy. ${ }^{3}$ 1IRCCS Fondazione Don Carlo Gnocch, Florence, Italy. ${ }^{4}$ Dipartimento Neuromuscolo-Scheletrico e degli Organi di Senso, SODc Neurofisiopatologia, AOU Careggi, Florence, Italy. ${ }^{5}$ Warwick Clinical Trials Unit, University of Warwick, Coventry, UK. ${ }^{6}$ Department of Anaesthesia and Intensive Care Medicine, Royal United Hospital, Bath, UK.
}

Table 1 Algorithm performance and proportion of patients with indeterminate outcome in three validation studies of the ERC-ESICM prognostication algorithm

\begin{tabular}{llllllll}
\hline Author [reference] & $\begin{array}{l}\text { Patients } \\
\text { entering the } \\
\text { algorithm }\end{array}$ & $\begin{array}{l}\text { Of whom } \\
\text { with poor out- } \\
\text { come, } \boldsymbol{n}(\%)\end{array}$ & $\begin{array}{l}\text { Poor outcome } \\
\text { predicted, } \boldsymbol{n}\end{array}$ & $\begin{array}{l}\text { Algorithm } \\
\text { sensitivity, \% }\end{array}$ & $\begin{array}{l}\text { FPR \% } \\
\text { Indeterminate } \\
\text { outcome, } \boldsymbol{n}(\%)\end{array}$ & $\begin{array}{l}\text { Of whom with neu- } \\
\text { rological recovery, } \\
\boldsymbol{n}(\%)\end{array}$ \\
\hline Zhou [3] & 207 & $174(84)$ & 48 & 28 & 0 & $159(77)$ \\
Bongiovanni [5] & 485 & $273(56)$ & 155 & 57 & 0 & $33(68)$ \\
Moseby-Knappe [6] & 205 & $191(93)$ & 103 & 54 & 0 & $102(50)$ \\
\hline
\end{tabular}




\section{Compliance with ethical standards}

\section{Conflicts of interest}

Claudio Sandroni is last author of the ERC-ESICM guidelines on post-resuscitation care, and co-author of one study mentioned in this Editorial. Jerry P. Nolan is first author of the ERC-ESICM guidelines on post-resuscitation care.

\section{Publisher's Note}

Springer Nature remains neutral with regard to jurisdictional claims in published maps and institutional affiliations.

Received: 30 July 2020 Accepted: 19 August 2020

Published online: 4 September 2020

\section{References}

1. Lemiale V, Dumas F, Mongardon N, Giovanetti O, Charpentier J, Chiche JD, Carli P, Mira JP, Nolan J, Cariou A (2013) Intensive care unit mortality after cardiac arrest: the relative contribution of shock and brain injury in a large cohort. Intensive Care Med 39:1972-1980

2. Nolan JP, Soar J, Cariou A, Cronberg T, Moulaert VR, Deakin CD, Bottiger BW, Friberg H, Sunde K, Sandroni C (2015) European resuscitation council and european society of intensive care medicine 2015 guidelines for post-resuscitation care. Intensive Care Med 41:2039-2056

3. Zhou SE, Maciel CB, Ormseth CH, Beekman R, Gilmore EJ, Greer DM (2019) Distinct predictive values of current neuroprognostic guidelines in post-cardiac arrest patients. Resuscitation 139:343-350

4. Wijdicks EF, Hijdra A, Young GB, Bassetti CL, Wiebe S (2006) Practice parameter: prediction of outcome in comatose survivors after cardiopulmonary resuscitation (an evidence-based review): report of the Quality Standards Subcommittee of the American Academy of Neurology. Neurology 67:203-210

5. Bongiovanni F, Romagnosi F, Barbella G, Di Rocco A, Rossetti AO, Taccone FS, Sandroni C, Oddo M (2020) Standardized EEG analysis to reduce the uncertainty of outcome prognostication after cardiac arrest. Intensive Care Med 46:963-972

6. Moseby-Knappe M, Westhall E, Backman S, Mattsson-Carlgren N, Dragancea I, Lybeck A, Friberg H, Stammet P, Lilja G, Horn J, Kjaergaard J, Rylander C, Hassager C, Ullen S, Nielsen N, Cronberg T (2020) Performance of a guideline-recommended algorithm for prognostication of poor neurological outcome after cardiac arrest. Intensive Care Med. https ://doi.org/10.1007/s00134-020-06080-9
7. Nielsen N, Wetterslev J, Cronberg T, Erlinge D, Gasche Y, Hassager C, Horn J, Hovdenes J, Kjaergaard J, Kuiper M, Pellis T, Stammet P, Wanscher M, Wise MP, Aneman A, Al-Subaie N, Boesgaard S, Bro-Jeppesen J, Brunetti I, Bugge JF, Hingston CD, Juffermans NP, Koopmans M, Kober L, Langorgen J, Lilja G, Moller JE, Rundgren M, Rylander C, Smid O, Werer C, Winkel P, Friberg $H$ (2013) Targeted temperature management at 33 degrees $C$ versus 36 degrees $C$ after cardiac arrest. N Engl J Med 369:2197-2206

8. Sandroni C, Nolan JP (2015) Neuroprognostication after cardiac arrest in Europe: new timings and standards. Resuscitation 90:A4-5

9. Geocadin RG, Callaway CW, Fink EL, Golan E, Greer DM, Ko NU, Lang E, Licht DJ, Marino BS, McNair ND, Peberdy MA, Perman SM, Sims DB, Soar J, Sandroni C, Care AHAEC, C, (2019) Standards for studies of neurological prognostication in comatose survivors of cardiac arrest: a scientific statement from the American Heart Association. Circulation 140:e517-e542

10. Scarpino M, Carrai R, Lolli F, Lanzo G, Spalletti M, Valzania F, Lombardi M, Audenino D, Contardi S, Celani MG, Marrelli A, Mecarelli O, Minardi C, Minicucci F, Politini L, Vitelli E, Peris A, Amantini A, Sandroni C, Grippo A (2020) Neurophysiology for predicting good and poor neurological outcome at 12 and $72 \mathrm{~h}$ after cardiac arrest: the ProNeCA multicentre prospective study. Resuscitation 147:95-103

11. Scarpino M, Lanzo G, Lolli F, Carrai R, Moretti M, Spalletti M, Cozzolino M, Peris A, Amantini A, Grippo A (2018) Neurophysiological and neuroradiological multimodal approach for early poor outcome prediction after cardiac arrest. Resuscitation 129:114-120

12. Hirsch LJ, Laroche SM, Gaspard N, Gerard E, Svoronos A, Herman ST, Mani R, Arif H, Jette N, Minazad Y, Kerrigan JF, Vespa P, Hantus S, Claassen J, Young GB, So E, Kaplan PW, Nuwer MR, Fountain NB, Drislane FW (2013) American Clinical Neurophysiology Society's standardized critical care EEG terminology: 2012 version. J Clin Neurophysiol 30:1-27

13. Paul M, Bougouin W, Geri G, Dumas F, Champigneulle B, Legriel S, Charpentier J, Mira JP, Sandroni C, Cariou A (2016) Delayed awakening after cardiac arrest: prevalence and risk factors in the Parisian registry. Intensive Care Med 42:1128-1136

14. Oddo M, Sandroni C, Citerio G, Miroz JP, Horn J, Rundgren M, Cariou A, Payen JF, Storm C, Stammet P, Taccone FS (2018) Quantitative versus standard pupillary light reflex for early prognostication in comatose cardiac arrest patients: an international prospective multicenter doubleblinded study. Intensive Care Med 44:2102-2111

15. Sandroni C, D'Arrigo S, Cacciola S, Hoedemaekers CWE, Kamps MA, Oddo M, Taccone FS, Di Rocco A, Meijer FA, Westhall E, Antonelli M, Soar J, Nolan JP, Cronberg T (2020) Prediction of poor neurological outcome in comatose survivors of cardiac arrest: a systematic review. Intensive Care Med. https://doi.org/10.1007/s00134-020-06198-w 